\title{
Pengelolaan Arsip Sesuai Standar Internasional (ISO 15489-1:2016) Studi Kasus Pengelolaan Arsip Bank Indonesia
}

\author{
Riko Priyatmo Ramudin \\ Arsip Nasional Republik Indonesia
}

\begin{abstract}
This article discusses Management of Records that adapts International Standards in the field of records, it is ISO 15489-1: 2016 on Documentation: Concepts And Principles - Records Management. Management of Records that compliance with international standards is very important for an organization to create authentic, reliable, complete and usable, so that it can support organizational performance. This article is important because until now there is only one institution in Indonesia that applies international standards in the field of records, Bank Indonesia. The aim of this research is to find out how to manage records in Bank Indonesia that compliance international standards (ISO: 15489-1: 2016). research method used is a qualitative method with primary and secondary data sources. Bank Indonesia Document Management Policy (MDBI) as a basis for Records Management according to international standards. MDBI refers to management of records which consists of policies and responsibilities, systems and processes.
\end{abstract}

Submitted: 07/10/2019

Received: 22/01/2020

*Correspondence: Riko P. Ramudin

rikopriyatmo@gmail.com

KEYWORDS:

Management of

Records

ISO 15489-1:2016

Process and Concept of Management of

Records

\section{INTISARI}

Artikel ini membahas Pengelolaan Arsip yang menyesuaikan Standar Internasional bidang kearsipan yakni ISO 15489-1:2016 tentang Documentation : Concepts And Principles - Records Management. Pengelolaan arsip yang sesuai standar internasional sangat penting bagi sebuah organisasi agar terciptanya arsip autentik, andal, utuh dan dapat digunakan, sehingga dapat mendukung kinerja organisasi. Artikel ini menjadi penting karena hingga saat ini hanya ada satu lembaga di Indonesia yang menerapkan standar internasional bidang kearsipan yakni Bank Indonesia. Adapun tujuan penelitian ini adalah mengetahui bagaimana pengelolaan arsip di lingkungan Bank Indonesia yang menyesuaikan standar internasional (ISO:154891:2016). Metode penelitian yang digunakan adalah metode kualitatif dengan sumber data primer dan skunder. Kebijakan Manajamen Dokumen Bank Indonesia (MDBI) sebagai dasar Pengelolaan Arsip sesuai standar internasional. MDBI acuan pengelolaan arsip yang terdiri dari kebijakan dan tanggung jawab, sistem dan proses.
KATA KUNCl: pengelolaan arsip

ISO 15489-1:2016

Proses dan Konsep Pengelolaan Arsip

CITE THIS ARTICLE:

Ramudin, Riko P. (2019).

Perkembangan

Pengelolaan Arsip

Sesuai Standar

Internasional (ISO 15489

$-1: 2016)$ Studi Kasus

Pengelolaan Arsip Bank

Indonesia. Jurnal

Diplomatika, 3(1), 14-25. 


\section{PENDAHULUAN}

Pengelolaan arsip merupakan tulang punggung bagi sebuah organisasi. Setiap kegiatan dalam organisasi menghasilkan arsip yang menjadi dasar sebagai bukti kegiatan dan alat bukti hukum yang sah. Untuk mencapai kedua hal tersebut dibutuhkan pengelolaan arsip yang baik.

Masalahnya tidak semua organisasi peduli akan pengelolaan arsip. Hal tersebut berdampak pada hilangnya arsip dan informasi di organisasi tersebut. Hilangnya arsip dan informasi lebih jauh berdampak ketidakpercayaan publik (mitra kerja, klien, dan masyarakat) bahkan organisasi tersebut akan mengalami kerugian berupa materi seperti hilangnya aset.

Pengelolaan arsip yang baik adalah pengelolaan yang mengacu pada prinsip dan standar baik nasional maupun internasional. Beberapa keuntungan bagi organisasi yang melaksaksanakan pengelolaan arsip mengacu pada prinsip dan standar yakni (ISO 15489, diterjemahkan SNI) :

1. Transparansi dan akuntabilitas;

2. Perumusan kebijakan yang efektif;

3. Pembuatan kebijakan yang efektif;

4. Pembuatan keputusan yang ditunjang informasi yang memadai;

5. Pengelolaan risiko pekerjaan:

6. Kesinambungan ketika terjadi bencana;

7. Perlindungan hak dan kewajiban organisasi dan perseorangan;

8. Perlindungan dan dukungan ligitasi;

9. Ketaatan undang-undang dan peraturan;

10. kemampuan yang meningkatan untuk menunjukkan tanggung jawab korporat, termasuk memenuhi tujuan keberkelanjutan;

11. pengurangan biaya melalui efisiensi pekerjaan yang berarti;

12. perlindungan terhadap hak atas kekayaan intelektual;

13. kegiatan penelitian dan pengembangan berbasis pembuktian;

14. pembentukan identitas pekerjaan, perseorangan dan budaya;

15. pembentukan identitas pekerjaan, perseorangan dan budaya.

Bank Indonesia sebagai lembaga pemerintahan yang independen menyadari akan pentingnya pengelolaan arsip yang baik. Untuk mencapai itu semua Bank Indonesia selain mengacu pada peraturan perundang-undangan yang berlaku, Bank Indonesia juga menerapkan standar internasional yakni ISO 30301:2011 Information and Documentation - Management Systems for Records - Requirements dan $598^{23}-1: 2016$ Information and documentation : concepts and principles - Records Management dalam mengelola arsip.

Bank Indonesia telah menerapkan ISO 30301:2011 dan 15489-1:2016 semenjak tahun 2014. Setelah proses audit tahun 2015 Bank Indonesia menerima sertifikat compliance dari Lembaga yang menerbitkan ISO. Selain Pusat divisi arsip ada ${ }^{0}$ unit kerja yang mendapatkan sertifikat yakni Depantermen Logistik dan Pengamanan, Departemen Audit Intern, Departemen Pengelolaan Aset, Kantor Perwakilan Wilayah Bank Indonesia (KPwBI) Propinsi Jawa Barat, Kantor Perwakilan Wilayah Bank Indonesia (KPwBI) Propinsi Daerah Istimewah Yogyakarta, dan KPwBI Propinsi Kepulauan Riau. BI merencanakan akan memperluas unit kerja yang mendapatkan compliance ISO.

Alasan Bank Indonesia menerapkan Standar Internasional untuk pengelolaan arsip yang tertib, sehingga arsip yang tercipta dan dikelolah dapat dibuktikan autentisitasnya, keutuhan, keandalan, dan digunakan untuk kebutuhan kegiatan 
organisasi.

Pada tahun 2017 Bank Indonesia mendapatkan penghargaan dari Arsip Nasional RI sebagai lembaga yang compliance ISO dibidang kearsipan. Pada tahun 2018 Bank Indonesia juga dinilai oleh Arsip Nasional RI sebagai Lembaga yang baik dalam pengelolaan arsip.

Pengelolaan Arsip Bank Indonesia menjadi contoh baik (best practice) untuk lembaga lainnya. Tulisan ini akan membahas masalah bagaimana penerapan standar internasional khususnya ISO 15489-1:2016 - Information and documentation : concepts and principles - Records Management, studi kasus pengelolaan arsip di Bank Indonesia, dan bagaimana kunci sukses implementasi ISO tersebut?

\section{METODE PENELITIAN}

Penelitian Pengelolaan Arsip sesuai ISO 15489-1:2016 - information and documentation : concepts and principles - Records Management di Bank Indonesia menggunakan penelitian kualitatif karena untuk dapat mengkaji lebih dalam pokok permasalahan dan informasi terkait. Fokus penelitian yakni pengelolaan arsip di Bank Indonesia yang mengacu Standar Internasional. Sumber data yang digunakan adalah data primer dan data skunder. Data primer didapat berdasarkan wawancara mendalam, observasi langsung, dan seminar langsung dengan pakar dari Bank Indonesia. Data Skunder didapatkan melalui referensi jurnal, buku, peraturan dan standar internasional.

Penelitian yang terkait adalah Penyusutan Arsip Dinamis Studi Kasus Bank Indonesia yang disusun oleh Eriza Anindy dari Universitas Islam Negeri Syarif Hidayatullah pada tahun 2018. Pembahasan penelitian terkait mengetahui bagaimana program penyusutan arsip dan mengidentifikasi kendala yang dihadapi arsiparis dalam penyusutan arsip di Bank Indoenesia.

\section{HASIL DAN PEMBAHASAN}

\section{Arsip dan Pengelolaan Arsip}

Menurut ISO 15489-1:20016, record is information created, received and maintained as evidence and as an asset by an organization or person, in pursuit of legal obligations or In the transaction of business. Sedangkan menurut Undang-Undang 43 tahun 2009 tentang Kearsipan menjelaskan bahwa arsip adalah rekaman kegiatan atau peristiwa dalam berbagai bentuk dan media sesuai dengan perkembangan teknologi informasi dan komunikasi yang dibuat dan diterima oleh lembaga negara, pemerintahan daerah, lembaga pendidikan, perusahaan,organisasi politik, organisasi kemasyarakatan, dan perseorangan dalam pelaksanaan kehidupan bermasyarakat, berbangsa dan bernegara.

Kemudian menurut Undang-Undang Republik Indonesia Nomor 8 Tahun 1997 tentang Dokumen Perusahaan, dokumen perusahaan adalah data, catatan, dan atau keterangan yang dibuat dan atau diterima oleh perusahaan dalam rangka pelaksanaan kegiatannya, baik tertulis di atas kertas atau sarana lain maupun terekam dalam bentuk corak apapun yang dapat dilihat, dibaca, atau didengar.

Konsep arsip diatas menyebutkan bahwa peran arsip bagi organisasi atau individu adalah untuk rekaman kegiatan, bukti legal transaksi, asset dan informasi. Sehingga untuk mencapai hal tersebut arsip harus dikelola dengan baik. ISO 15489-1:2016, 
kegiatan pengelolaan arsip meliputi :

a. Menciptakan dan menangkap arsip untuk memenuhi syarat sebagai bukti kegiatan pekerjaan;

b. Mengambil tindakan yang tepat untuk melindungi keotentikan, keandalan, integritas, dan ketergunaannya sebagai informasi pekerjaan dan syarat untuk menghadapi perubahan dalam pengelolaan arsip sepanjang waktu.

Sedangkan menurut Undang-Undang Nomor 43 Tahun 2009 tentang Kearsipan menjelaskan bahwa pengelolaan arsip terdiri dari pengelolaan arsip dinamis dan pengelolaan arsip statis. Pengelolaan arsip dinamis, meliputi penciptaan, penggunaan dan pemeliharaan, dan penyusutan arsip. sedangkan pengelolaan arsip statis, meliputi akuisisi arsip statis, pengolahan arsip statis, preservasi arsip statis, dan akses arsip statis.

Arsip sebagai bukti dan juga sekaligus sumber informasi, sehingga perlu juga ditimbang perihal nilai guna berkesinambungan (continuing value) yang dikandung oleh arsip. nilai guna berkesinambungan ini erat kaitannya dengan memori kolektif yang harus dilestarikan. Dalam pandangannya, Ellis mengkonsepsikan continuing value sebagai (Ellis,1993):

a. Suatu sumber memori untuk jangka waktu yang panjang;

b. Suatu cara mendapatkan pengalaman yang lain;

c. Suatu bukti akan adanya hak dan kewajiban yang berkelanjutan;

d. Suatu instrument kekuasaan, legitimasi dan pertanggungjawaban;

e. Suatu gambar pemahaman dan proses identifikasi terhadap diri kita sendiri, organisasi dan masyarakat; dan

f. Satu sarana untuk mengkomunikasikan nilai-nilai politis, social dan budaya.

Kemudian Penn menyebutkan bahwa manajemen kearsipan/pengelolaan arsip memiliki fungsi untuk (Penn,1992):

a. Mengontrol kualitas dan kuantitas arsip yang diciptakan.

b. Mengelola secara efektif arsip yang ada sehingga mampu melayani kebutuhan organisasi akan informasi; dan

c. Menyelenggarakan proses penilaian dan penyusutan arsip yang tidak lagi dibutuhkan oleh organisasi.

Kemudian Patricia Wallace menjelaskan pentingnya manajemen kearsipan atau pengelolaan arsip yang berkesinambungan terkait dengan arsip dinamis dan arsip statis. Dalam pandangannya, Wallace menilai bahwa pengendalian secara sistematis atas daur hidup arsip dari penciptaan sampai dengan pemusnahan akhir atau penyimpanan arsip permanen itu penting (Wallace, 1992).

\section{Konsep dan Prinsip ISO 15489-1:2016}

Sebelum membahas pengelolaan arsip Bank Indonesia terlebih dahulu membahas isi dari ISO 15489-1 : 2016 - information and documentation : concepts and principles. Ruang lingkup ISO 15489-1:2016 meliputi konsep dan prinsip yang menjadi dasar pendekatan penciptaan, penangkapan, dan pengelelolaan arsip harus dikembangkan. 
Perlu kita ketahui bahwa ISO 15489-1:2016 tidak memandang bentuk arsip dan media arsip. Pengelolaan arsip disini lebih diartikan pada arsip dinamis baik aktif dan inaktif. Sehingga Konsep dan prinsip tersebut berhubungan dengan hal yakni:

\section{a. Arsip, metadata untuk arsip dan sistem kearsipan;}

Arsip tidak hanya menjadi sebuah rekaman peristiwa, pada perkembangannya arsip sebagai bukti kegiatan dan asset informasi. Untuk itu sebuah arsip harus memiliki ciri otentik, andal, utuh dan dapat digunakan.

Ciri arsip di atas direkam dalam sebuah metadata dimana metadata sebaiknya berisi informasi beberapa hal berikut:

1. deskripsi arsip;

2. struktur arsip (misalnya, bentuk, format dan hubungan antara komponen yang membentuk arsip) ;

3. konteks pekerjaan arsip diciptakan atau diterima dan digunakan;

4. hubungan dengan arsip lain dan metadata lain;

5. penciri dan informasi lain diperlukan untuk menemukan dan menyajikan arsip seperti format atau informasi penyimpanan;

6. tindakan pekerjaan dan kejadian yang melibatkan arsip sepanjang keberadaannya (termasuk tanggal dan waktu tindakan, perubahan pada metdata dan pihak yang melakukan tindakan).

b. Kebijakan, tanggung jawab yang dibebankan, pemantauan dan penelitian yang mendukung pengelolaan arsip yang efektif;

1. kebijakan

Setiap organisasi harus memiliki kebijakan umum tentang pengelolaan arsip. kebijakan tersebut harus dikembangkan, didokumentasikan, dan diterapkan. Sebaiknya kebijakan pengelolaan arsip meliputi ruang lingkup seperti aspek pengelolaan arsip, standar atau aturan yang berlaku dan ketentuan audit dan sebaiknya menyebut kegiatan pekerjaan yang diatur. Kemudian kebijakan ditinjau secara berkala untuk memastikan bahwa kebijakan mencerminkan keperluan pekerjaan terkini.

2. Tanggung jawab

Tanggung jawab dan wewenang dalam pengelolaan arsip sebaiknya ditentukan, ditunjuk dan diumumkan. Kemudian tanggung jawab sebaiknya dibebankan kepada seluruh personil yang menciptakan dan menggunakan arsip sebagai bagian dari pekerjaan mereka dan sebaiknya dinyatakan dalam uraian tugas dan informasi sejenisnya. Penunjukan perseorangan yang bertanggung jawab sebaiknya disahkan secara hukum. Tanggung jawab kepemimpinan yang lebih tinggi untuk pengelolaan arsip sebaiknya dibebankan kepada perorangan yang mempunyai wewenang yang sesuai seperti pejabat senior.

3. Pemantauan dan evaluasi;

Kebijakan pengelolaan arsip seharusnya dilakukan pemantauan dan evaluasi, pemantauan dan evaluasi terdiri dari kebijakan, sistem, prosedur dan proses arsip. Pemantauan dan evaluasi dirancang untuk menjamin bahwa :

a) sistem dan proses arsip diterapkan sesuai dengan kebijakan dan syarat pekerjaan yang sah;

b) sistem dan proses arsip bekerjaan sebagaimana ditetapkan dan dirancang;

c) pengubahan terhadap syarat arsip dipenuhi;

d) terdapat peningkatan terus-menerus dalam pengelolaan arsip.

Rancangan program pemantauan dan evaluasi sebaiknya 
a) menunjuk penanggung jawab kegiatan pemantauan dan evaluasi;

b) menentukan apa yang perlu dipantau dan dievaluasi;

c) menetapkan metode pengukuran, pemantauan, analisis dan evaluasi untuk menjamin hasil yang sahih;

d) menentukan kapan pemantauan dan evaluasi sebaiknya dilakukan;

e) menentukan kapan hasil pemantauan sebaiknya dianalisis dan dievaluasi;

f) menunjuk penanggung jawab perumusam tindakan yang tepat;

3. Kompetensi dan pelatihan

Orang yang diberi tanggung jawab yang berkaitan dengan pengelolaan arsip sebaiknya kompeten dalam melaksanakan tugas. Kompetensi dievaluasi secara ajeg dan program pelatihan untuk mengembangkan dan meningkatkan kompetensi dan keterampilan sebaiknya disusun dan dilaksanakan bila diperlukan. Program pelatihan terus dilaksanakan dan meliputi pelatihan mengenai persyaratan, kebijakan, praktik, peran dan tanggung jawab dalam mengelola arsip, dan diikuti oleh semua anggota organisasi dan pegawai, serta perorangan lain yang bertanggung jawab atas bagian apa pun dari kegiatan pekerjaan yang berhubungan dengan pengelolaan arsip.

\section{c. Analisis berkelanjutan dari konteks pekerjaan dan identifikasi syarat arsip;}

Analisis dan identifikasi syarat arsip merupakan proses kegiatan untuk menentukan arsip yang diciptakan dan dikelolah seberapa lama arsip perlu disimpan. Analisis menggabungkan pemahaman konteks pekerjaan dengan penentuan syarat untuk bukti kegiatan sebaiknya dipenuhi melalui arsip. analisis meliputi kegiatan sebagai berikut :

1. mengembangkan pemahaman mengenai sifat pekerjaan dan latar hukum, penyediaan sumber daya dan teknologi;

2. menggunakan penilaian resiko untuk menentukan arsip yang sebaiknya diciptakan dan bagaimana arsip sebaiknya dikelola untuk memenuhi syarat yang dapat diterapkan. Risiko ini meliputi:

a) risiko yang mempengaruhi pekerjaan secara umum, dan

b) risiko yang dapat diatasi melalui penciptaan, penangkapan dan pengelolaan arsip;

Sedangkan untuk persyaratan arsip didasarkan pada analisis kegiatan pekerjaan dan konteksnya dan beasal dari hal-hal berikut :

1. kebutuhan pekerjaan;

2. persyaratan legal dan regulasi;

3. harapan komuntas atau masyarakat.

\section{d. Pengendalian arsip;}

Pengendalian arsip meliputi hal sebagai berikut :

1. skema metadata untuk arsip;

skema metadata merupakan rencana logis yang menunjukkan hubungan antara elemen metadata, biasanya dengan penetapan aturan mengenai penggunaan dan pengelolaan metadata yang secara khusus memperhatikan semantik, sintaks, dan pilihan (tingkat kewajiban) nilai. Entitas utama pengelolaan arsip adalah sebagai berikut:

a) arsip - meliputi semua tingkat agregasi;

b) agen- meliputi orang, unit kerja, teknologi atau sistem pekerjaan dan 

c) pekerjaan (atau fungsi)- fungsi, kegiatan dan transaksi atau proses kerja;
d) mandate-hukum dan ketentuan lain yang mengatur cara menjalankan kegiatan serta penciptaan dan pengelolaan arsip;
e) hubungan-antara berbagai entitas dan berbagai lapisan agregasi.

2. kerangka klasifikasi pekerjaan;

skema klasifikasi pekerjaan merupakan alat untuk menghubungkan arsip dengan konteks penciptaannya.

3. aturan akses dan izin;

aturan akses dan izin berhubungan dengan unsur berikut :
a) pihak;
b) kegiatan pekerjaan;
c) arsip;

4. wewenang penyusutan;

wewenang penyusutan merupakan instrument yang menjelaskan tindakan penyusutan yang diizinkan untuk arsip tertentu. Wewenang penyusutan dibentuk untuk mengatur penyusutan arsip. tanggung jawab atas penetapan wewenang penyusutan sebaiknya sesuai dengan hukum, peraturan dan kebijakan. Kemudian wewenang penyusutan seharusnya disahkan, ditentukan masa berlakunya, diterapkan dan ditinjau secara berkala agar selalu mengikuti perubahan syarat.

\section{e. Proses penciptaan, penangkapan dan pengelolaan arsip.}

proses ini mencakup :

1. menciptakan arsip;

2. menangkap arsip;

3. klasifikasi dan pengindeksan;

4. pengendalian akses;

5. menyimpan arsip;

6. penggunaan dan penggunaan ulang;

7. migrasi atau konversi;

8. penyusutan.

\section{Penerapan ISO 15489-1 : 2016 di Lingkungan Bank Indonesia.}

Bank Indonesia membuat kebijakan kearsipan melalui peraturan internal yang tertuang pada Surat Edaran Internal Gubernur Bank Indonesia 18/ 125/ 2016 tentang Manajemen Dokumen Bank Indonesia (MDBI). MDBI menjadi pedoman bagi organisasi BI di tingkat pusat dan seluruh kantor perwakilan baik tingkat Provinsi maupun Kota/ Kabupaten untuk melakukan pengelolaan dokumen dan arsip. Ruang lingkup MDBI adalah semua dokumen atau arsip yang dibuat dan diterima oleh Bank Indonesia berbentuk dokumen nonelektronik maupun dokumen elektronik. MDBI berlaku untuk seluruh pegawai dan pihak lain yang ditunjuk atau disetujui oleh Bank Indonesia untuk melakukan tugas tertentu, di satuan kerja di kantor pusat, kantor perwakilan Bank Indonesia dalam negeri, dan kantor perwakilan Bank Indonesia Luar Negeri. Adapun tujuan dari MDBI yakni :

a. menyediakan dokumen autentik, legal dan terpercaya;

b. memberikan keamanan, ketersediaan dan kemudahan arsip bank indonesia;

c. mewujudkan pengelolaan dokumen yang efektif, efisien, dan selekstif sesuai dengan sistem kearsipan nasional serta memenuhi standar internasional 
kearsipan

d. Mendukung akuntabilitas dan transparansi pelaksanaan tugas dan wewenang Bank Indonesia;

Sedangkan prinsip-prinsip dari MDBI adalah :

a. Semua dokumen yang berkaitan dengan tugas dan fungsi Bank Indonesia adalah milik Bank Indonesia;

b. Dokumen terkait kebijakan Bank Indonesia dalam menjalankan tugas dan fungsinya dikategorikan sebagai arsip terjaga Bank Indonesia, dipindahkan dan disimpan di SKA KP atau SKA KPW, serta dilakukan alih media.

c. Penyimpanan arsip Bank Indonesia dilakukan secara selektif, antara lain untuk menghindari duplikasi arsip.

d. Penyimpanan dan penyusutan arsip Bank Indonesia dilakukan dengan berpedoman kepada Klasifikasi Masalah, Jadwal Retensi Arsip Bank Indonesia (KMJRABI) yang ditetapkan oleh satuan kerja yang membidangi kearsipan, sesuai dengan usulan satker.

e. Arsip elektronik yang belum memiliki JRA dalam KMJRABI, penentuan retensinya mengikuti retensi dokumen nonelektronik atau JRA yang sejenis arsip elektronik tersebut.

f. Pelaksanaan MDBI dengan menggunakan aplikasi BI-RMS

g. Penyampaian laporan perkembangan volume arsip Bank Indonesia kepada Anggota Dewan Gubernur yang membawahkan Satuan Kerja Kearsipan

Untuk tanggung jawab MDBI dilakukan oleh seluruh pegawai Bank Indonesia atas dokumen hasil pekerjaannya secara akurat, lengkap, dan memastikan dokumen dikelola sesuai ketentuan MDBI. Pimpinan Divisi Arsip menetapkan standar, kebijakan dan petunjuk pelaksanaan pengelolaan dokumen. Kemudian pimpinan satuan kerja memastikan pengelolaan dokumen di lingkungan kerjanya sesuai ketentuan MDBI dan memastikan pegawai di lingkungan kerjanya memahami dan mematuhi ketentuan MDBI.

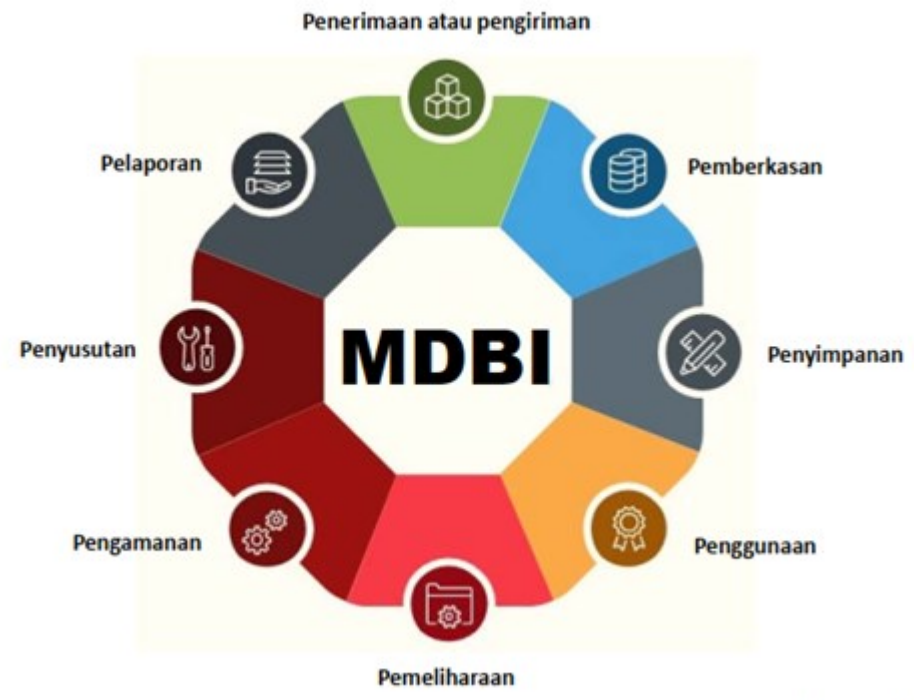

\section{Gambar 1. Manajemen Dokumen Bank Indonesia}

Berdasarkan aturan MDBI proses pengelolaan arsip terdiri dari Penerimaan atau pengiriman, Pemberkasan, Penyimpanan, Penggunaan, Pemeliharaan, Pengamanan, Penyusutan, Pelaporan. Setiap proses tersebut harus menyesuaikan konsep dan prinsip ISO 15489:1-2016. Setiap tahap tersebut harus dipastikan input, proses dan bukti yang sesuai standar. Adapun input, proses dan bukti setiap proses sebagai berikut: 


\section{a. Penerimaan/pengiriman}

1. Penerimaan/pengiriman dokumen telah menggunakan daftar pengantar atau buku pengantar;

2. Pencatatan penerimaan/pengiriman dokumen dilakukan secara konsisten dalam Daftar Dokumen Masuk (DDM) dan Daftar Dokumen Keluar (DDK)

3. Bukti penerimaan/pengiriman dokumen telah diberkas kan secara series:

- Daftar Pengantar (DP)

- Daftar Dokumen Masuk (DDM)

- Daftar Dokumen Keluar (DDK)

4. Penerimaan dokumen di UP dibubuhkan time stamp (dengan mesin time stamp atau secara manual)

5. Pengiriman dokumen dari UP ke pihak eksternal menggunakan Daftar Pengantar Dokumen Eksternal (DPDE).

\section{b. Pemberkasan}

1. Dokumen telah diberkas ke dalam folder, ordner, bundle atau media penyimpanan lainnya. Pemberkasan dapat dikelompokan berdasarkan masalah atau kesamaan jenis dokumen dan diurutkan per tanggal dokumen.

2. Dokumen telah diberkas:

a) Diberi Tanda Pengenal Pelengkap (TPP) yaitu; perihal, Klasifikasi Masalah dan Jadwal Retensi Arsip Bank Indonesia (KMJRABI), dan Tahun Dokumen.

b) Dilengkapi Daftar Arsip.

c) Diberi Nomor Urut Sesuai dengan Daftar Arsip

3. Pemberian KMJRABI, diatur sebagai berikut :

a) Dokumen periode 2016 dan sebelumnya menggunakan kode klasifikasi sebagaimana pada Lampiran IV SE MDBI No. 18/125/ INTERN tanggal 30 Desember 2016 tentang Manajemen Dokumen Bank Indonesia (MDBI), atau 6 digit.

b) Dokumen periode tahun 2017 dan sesudahnya menggunakan Kode Klasifikasi sebagai pada Lampiran III SE MDBI No 18/125 Intern tanggal 30 Desember 2016 tentang Manajemen Dokumen Bank Indonesia (MDBI), atau 8 digit.

\section{c. Penyimpanan}

1. Seluruh sarana simpan arsip telah diberi alamat lokasi simpan, yaitu; Nama Satker/Nama Divisi/Jenis Sarana Simpan/No Urut Sarana Simpan Arsip/ No Urut Laci atau Hambalan. Contoh : DPLF/PS/FC/03/01

2. Berkas arsip yang telah di input dalam BI-RMS, disimpan dalam sarana simpan sesuai peruntukannya yaitu :

a) Folder disimpan di Filling Cabine (FC)

b) Odner, bundel temple, dan binder disimpan dalam storage cabinet (SC), Rak Statis, Roll O'Pack.

c) Arsip gambar disimpan di Lemari Gambar (LG)

d) CD, catrige, dan Gash disk disimpan dalam lemari dokumen elektronik antara lain dry box atau lemari khusus untuk dokumen elektronik.

e) Kotak arsip disimpan di dalam RollO'Pack atau Storage Cabinet.

3. Lokasi simpan fisik berkas arsip sesuai dengan data di BI-RMS

\section{d. Peminjaman/Penggunaan}

1. Peminjaman arsip oleh Pihak Eksternal 
Menggunakan Bon Pinjam Arsip, copy Bon Pinjam arsip diletakkan di lokasi atau tempat dimana berkas arsip semula disimpan

2. Peminjaman arsip oleh Pihak Eksternal Berdasarkan surat permintaan peminjaman

3. Untuk peminjaman arsip yang disimpan di Sentral Khazanah Arsip (SKA).

a) Dicatat pada Daftar Peminjaman Arsip

b) Memonitor jangka waktu peminjaman arsip.

\section{e. Penyiangan}

1. Pemindahan Arsip

a) Pemindahan berkas arsip menggunakan kotak arsip atau sarana simpan lainnya sesuai dengan jenis arsip yang dipindahkan

b) Kotak arsip harus dilengkapi dengan Daftar Isi Kotak (DIK) dan disegel dengan dibubuhi tanggal dan paraf pejabat pejabat Unit Pengelola (UP) pada label segel

c) Berkas dokumen belum habis JRA

d) Menggunakan Daftar Arsip yang dipindahkan (DAP)

2. Pemusnahan

Arsip yang dimusnahkan adalah arsip yang :

a) Telah habis jadwal Retensinya

b) Tidak mempunyai nilai guna

c) Tidak sedang terkait kasus Hukum

d) Tidak ada peraturan perundang-undang yang melarang.

Untuk dokumen dengan Jadwal Retensi (JR):

10 tahun atau lebih;

a) Membuat Daftar Arsip yang akan Dimusnahkan (DAM)

b) Membentuk Panitia Penliaian Arsip (PPA)

c) Membuat Berita Acara Penilaian Arsip (BANA)

d) Membuat Berita Acara Pemusnahan Arsip (BAMA)

Dibawah 10 tahun

a) Membuat DAM

b) Membuat BAMA

Pengajuan pemusnahan arsip dilakukan pejabat atau pegawai yang diberi kewenangan sebagai Kepala Unit dan persetujuan pemusnahan arsip dilakukan Pejabat setingkat kepala tim.

\section{f. Pengamanan / Clean Desk Policy}

1. Tersedianya APAR dan Kartu Kontrol APAR yang di cek setiap bulan.

2. Pengendalian akses keluar masuk ruang kerja (RSA)/Khazanah Buku dan SKA

3. Sarana simpan arsip dalam kondisi terkunci

4. Anak-anak kunci sarana simpan beri identitas disimpan dalam box kunci. Kunci box disimpan oleh pejabat/PIC

5. Memasang tanda/tulisan "DILARANG MEMBAWA TAS, MEROKOK, MAKAN DAN MINUM DI RUANG SKA"

6. Menyimpan dokumen setelah jam kerja berakhir dengan prinsip 3R yaitu Rapi, Resik dan Ringkas.

7. Menyediakan tanda jalur evakuasi dan penanganan keadaan darurat

\section{g. Pemeliharaan}

Pemeliharaan berkas arsip dilakukan dengan : 
1. Pemeliharaan berkas arsip di lakukan dengan;

2. Memiliki Jadwal Pemeliharaan Arsip khusus di RSA dan SKA

a) Suhu udara di RSA antara $18^{\circ}-22^{\circ}$ dan kelembaban 50\% RH - 70\% RH

b) Ruang SKA terjaga dari masuknya serangga dan sinar matahari

c) Melakukan pest control secara berkala di ruang SKA.

\section{h. Pelaporan}

1. Telah melakukan perhitungan volume arsip Satker secara benar dan akurat

2. Telah menyampaikan Laporan Perkembangan Arsip Bank Indonesia ke Divisi Arsip Kantor Pusat tepat waktu per semester.

\section{KESIMPULAN}

Bank Indonesia telah menerapkan ISO 30301:2011 dan 15489-1:2016 semenjak tahun 2014. Setelah proses audit tahun 2015 Bank Indonesia menerima sertifikat compliance dari Lembaga yang menerbitkan ISO. Tujuan dari penerapan ISO tersebut yakni pengelolaan arsip yang tertib, sehingga arsip yang tercipta dan dikelolah dapat dibuktikan autentisitasnya, keutuhan, keandalan, dan digunakan untuk kebutuhan kegiatan organisasi.

Penerapan 15489-1:2016 di lingkungan Bank Indonesia di akomodir melalui kebijakan Manajemen Dokumen Bank Indonesia (MDBI). Adapun tujuan dari MDBI adalah:

1. menyediakan dokumen autentik, legal dan terpercaya;

2. memberikan keamanan, ketersediaan dan kemudahan arsip bank indonesia;

3. mewujudkan pengelolaan dokumen yang efektif, efisien, dan selekstif sesuai dengan sistem kearsipan nasional serte serta memenuhi standar internasional kearsipan

4. Mendukung akuntabilitas dan transparansi pelaksanaan tugas dan wewenang Bank Indonesia;

Konsep dan prinsip ISO 15489-1:2016 dalam mengelola arsip yakni menciptakan, menangkap, dan mengelola arsip yang tergambar di dalam proses pengelolaan arsip Bank Indonesia yang terdiri dari dari Penerimaan atau pengiriman, Pemberkasan, Penyimpanan, Penggunaan, Pemeliharaan, Pengamanan, Penyusutan, Pelaporan. Setiap tahap tersebut harus dipastikan input, proses dan bukti yang sesuai standar. Setiap proses selalu ada input, bukti dan terdokumentasi.

Salah satu kunci suksesnya pengelolaan arsip di lingkungan Bank Indoenesia adalah awareness oleh pimpinan dan pegawai Bank Indonesia. Awareness tersebut diikut oleh kebijakan pengelolaan arsip yang diinternalisasi pada Indeks Kinerja Unit Kerja. Sehingga masing-masing unit kerja di lingkungan Bank Indonesia berlomba-lomba untuk membenahi dan mengelola arsip yang baik. Selain itu setiap tahunnya unit kerja yang terbaik dalam pengelolaan arsip akan mendapatkan pengharagaan dari Dewan Gubernur Bank Indonesia.

\section{DAFTAR PUSTAKA}

Wallace, P. E. (1992). Records Management Intregated Information Systems. New Jersey: Prentice Hall Inc.

Ellis, J. (1993). Keeping Archives. Port Melbourne: Thorpe and Australian Society of Archivist.

Undang-Undang Republik Indonesia Nomor 8 Tahun 1997 tentang Dokumen Perusahaan

Undang - Undang Republik Indonesia 43 Tahun 2009 tentang Kearsipan 
Undang - Undang Republik Indonesia Nomor 23 Tahun 2014 tentang Pemerintahan Daerah

ISO 15489-1:2016 information and documentation : concepts and principles.

Pusat Pengkajian dan Pengembangan Sistem Kearsipan (2017). Tata Kelola E-Arsip. Jakarta : Arsip Nasional Republik Indonesia.

Badan Standardisasi Nasional.(2018). SNI 8642:2018 ISO 15489-1:2016 Informasi dan Dokumentasi-Pengelolaan Arsip-Bagian 1: Konsep dan Prinsip. Jakarta : Badan Standardisasi Nasional

Departemen Pengelolaan Logisitik \& Fasilitas. (2019) "Records Management System (BI-RMS)". Jakarta : Bank Indonesia.

Departemen Pengelolaan Logisitik \& Fasilitas. (2019). ISO 15489 - RECORDS MANAGEMENT. Jakarta : Bank Indonesia 